\title{
Response to the comment on the article entitled "Balloon atrial septostomy in pulmonary arterial hypertension: A beneficial effect on the control of rhythm abnormalities" [1]
}

\author{
Katarzyna Małaczyńska-Rajpold \\ $1^{\text {st }}$ Department of Cardiology, Poznan University of Medical Sciences, Poznan, Poland
}

Balloon atrial septostomy (BAS) is a palliative procedure, but actually, interatrial shunt tends to be self-closing within a few months. However, in countries with a large number of donors, time to lung transplantation (LuTx) for a patient on a waiting list it is approximately 2-4 months [2]. Such a short waiting time allows the procedure to be performed only once or even offers the possibility of extracorporeal membrane oxygenation if the patient requires bridging treatment [3]. In cases with an essentially longer waiting list, there is a need for methods which allow a deteriorating patient to survive for a year or even up to 2 years. Using one of the devices available on the market in addition to BAS, to keep the interatrial connection opened within this time period, prevents the patient from having the procedure repeated. These devices are very promising - especially the atrial flow regulator (AFR) invented by Vettukattil's group [4]. However, currently, some significant disadvantages exist comprising: i) the limited availability for commercial use, ii) high price and iii) lack of reimbursement for the procedure.

Patients disqualified from LuTx would probably benefit significantly from the implantation of such a device as their life would be prolonged without the need for repeated invasive BAS procedure [5]. On the other hand, however, there are patients referred for LuTx for which another question arises: what to do with such devices in patients undergoing LuTx. The only device which is retrievable is the AFR. However, after a period of implantation, the device gets endothelialized and retrieval becomes impossible. Thus, the only remaining option seems to be an AFR closure with an atrial septal occluder or vascular plug. But when? During transplantation or some time later? Perhaps such a patent connection between the atria could be helpful in the initial period after $\mathrm{LuTx}$, because the flow direction in the shunt would reverse, causing a bigger preload and in this way improving its function before adapting to the lower vascular resistance of the new lungs. The current ongoing multicenter trial in which the AFR device is being tested will perhaps tell us more precisely, how to face these challenges.

Conflict of interest: None declared

\section{References}

1. Małaczyńska-Rajpold K, Araszkiewicz A, Mularek-Kubzdela T. Balloon atrial septostomy in pulmonary arterial hypertension: A beneficial effect on the control of rhythm abnormalities. Cardiol J. 2016; 23(5): 539-540, doi: 10.5603/CJ.2016.0075.

2. Kistler KD, Nalysnyk L, Rotella P, et al. Lung transplantation in idiopathic pulmonary fibrosis: a systematic review of the literature. BMC Pulm Med. 2014; 14: 139, doi: 10.1186/1471-2466-14139, indexed in Pubmed: 25127540.

3. Gulack BC, Hirji SA, Hartwig MG. Bridge to lung transplantation and rescue post-transplant: the expanding role of extracorporeal membrane oxygenation. J Thorac Dis. 2014; 6(8): 1070-1079, doi: 10.3978/j.issn.2072-1439.2014.06.04, indexed in Pubmed: 25132974.

4. Patel MB, Samuel BP, Girgis RE, et al. Implantable atrial flow regulator for severe, irreversible pulmonary arterial hypertension. EuroIntervention. 2015; 11(6): 706-709, doi: 10.4244/EIJY15M07_08, indexed in Pubmed: 26477643.

5. Kurzyna M, Dabrowski M, Bielecki D, et al. Atrial septostomy in treatment of end-stage right heart failure in patients with pulmonary hypertension. Chest. 2007; 131(4): 977-983, doi: 10.1378/ chest.06-1227, indexed in Pubmed: 17426198.

Address for correspondence: Katarzyna Małaczyńska-Rajpold, MD, PhD, $1^{\text {st }}$ Department of Cardiology, Poznan University of Medical Sciences, ul. Długa 1/2, 61-848 Poznań, Poland, tel: +48 6185491 46, fax: +48 6185490 94, e-mail: katarzyna.rajpold@skpp.edu.pl 